\title{
Human Resource Management Modes and the Selection Factors
}

\author{
Sha Zhang \\ Huanghe Science \& Technology College; Zhengzhou 450006, China
}

\begin{abstract}
In the modern times, competitions in various industries become increasingly intense with the rapid development of society. The brain drain is also becoming more and more serious. The enterprise generally suffers great losses caused by the brain drain, because it has spent much time and money on personnel training. Therefore, it has been the duty of every human resource manager to select an appropriate human resource management mode and try the best to retain every talent, with the purpose of promoting the comprehensive development of the enterprise. The human resources management of many enterprises in China is not mature enough and there are often various problems. Starting with the human resources, the author interprets human resource management modes and gives a comprehensive analysis to selection factors of the human resource management mode. Moreover, the reason analysis of some problems of human resources management in China and corresponding solutions will also be offered in this paper.
\end{abstract}

Keywords: human resources; the brain drain; human resource management.

\section{Introduction}

Manpower is fundamental to an enterprise while the existence of the human resources (HR) is the key to the development of the enterprise. Thus, the enterprise must pay more attention to human resource management (HRM). At present, there are still problems in many aspects of Chinese HRM, because its development is not mature enough. This is a "short board" for Chinese enterprises in their development. This short board must be made up to promote the better and faster development of enterprises. Only by this way can the enterprise keep in step with the era development to achieve success in the economic war, avoiding being eliminated by the law of survival of the fittest. Retaining talents is the responsibility of every HR manager and it is also the root of progress for every enterprise. In this sense, to improve HRM has become a task very urgent at present.

\section{Necessity of Human Resource Management}

The HRM mode refers to that an enterprise applies comprehensive analysis and planning on all its members and then carries out corresponding changes according to the specific duty of jobs as well as the department contribution to the enterprise, aiming to make the enterprise talents play their role and realize their values to the maximum extent. This will also support the enterprise get the best development. Therefore, HRM is extremely important for the enterprise if it want to obtain good development.

\section{Human Resource Management Modes}

The enterprise HRM mode can be divided from a variety of perspectives and each perspective contains several modes.

(1) Based on the objective of management, the management mode can be divided into comprehensive HRM, targeted HRM, personnel HRM and professional HRM. Managers need to choose the management mode according to the objective of management.

(2) Based on the management method taken, the management mode can be divided into empirical HRM, constructive HRM, systematic HRM and performance HRM.

(3) Based on the process of management, the management mode can be divided into comprehensive HRM, professional HRM, functional HRM and optimal HRM. This division of this kind is to achieve the balance of management work in various aspects, so as to make the management get the best effect. 
(4) Based on the content of the management, the management mode can be divided into internal HRM, external HRM, constructive HRM and skilled HRM. This covers the management of the team and individuals.

\section{Problems Existing in the Human Resources Management Modes}

\subsection{Incomplete management concept}

In the modern society, the business model of enterprises is in the constant innovation. Meanwhile, the application of technologies and equipment is also constantly reformed. Enterprises continue to move forward driven by the age. However, some enterprises do not implement reform timely in the HRM development. They follow some stereotypical management modes and neglect the innovation of HRM. As a result, they have not yet achieved modernization at present. For examples, their internal wage system is not perfect enough; methods of future planning and necessary training for employees are unsound. This not only inhibits the growth of the enterprise's employees, but also makes the work of HRM department become more difficult, making it harder for the enterprise to comply with the development of the times.

\subsection{Unreasonable incentive mechanism}

In the developing process, some enterprises determine staff's salary level simply according to their respective position and specific daily work while ignoring the incentive for the staff. Due to the absence of a completely fair salary system, the work passion and autonomy of staff cannot be aroused effectively. Since staff's performance accounts for a rather small proportion of their salary, their work enthusiasm is largely repressed, which hinders the sustainable development of the enterprise. Therefore, enterprises should adopt effective reasonable means to change the existing state, so as to gain rapid development.

\subsection{Incomplete method for talent introduction and training}

At present, with the increasingly fierce competitions between enterprises, requirements upon staff in different industries are also becoming higher. The enterprise HRM should also keep up with the trend to introduce targeted talents effectively. Some enterprises, however, totally ignore this problem. They neither introduce talents timely nor pay enough attention to the talent introduction, limiting the development of their own. Some enterprises do not establish good and reasonable mechanism for personnel training, which not only hinders the enhancement of staff's work ability, but also hinders the further development of HRM. Thus, these enterprises should take measures timely to achieve reform.

\section{Selection Factors of The Human Resource Management Mode}

\subsection{Scale of the enterprise}

Enterprises must have a comprehensive and overall understanding of their own scale before select the HRM mode, in order to maximize the management effects. It is the unshirkable responsibility for every HR manager to select a management mode appropriate for enterprise development. The enterprise need to persist in the principle of stability on the basis of enterprise scale, because a changing management mode will make staff feel strongly unsettled. At the same time, the enterprise should make reasonable adjustment according to the different stage of enterprise scale development to give full play to HR.

\subsection{Strategic objective}

A reasonable planning for development of the enterprise describing the enterprise's future prospect can enhance staff's work motivation and promote better development of the enterprise. The strategic objective is the overall planning for the enterprise development, guiding the enterprise development in various aspects. It is extremely important for the enterprise to develop a reasonable strategic objective. HR managers must follow the development strategy of the enterprise at work to select various talents suitable for the enterprise's future development. 


\subsection{Enterprise ownership}

In the era in rapidly developing, a variety of business modes continues to emerge. The vigorous development of state-owned enterprises, joint ventures, private enterprises and foreign-funded enterprises plays an immeasurable role in the economic development of China. It is necessary to carry out reasonable HRM to make the development of enterprises more efficient, promoting the continuous synchronous development of the society and individuals. In order to understanding the impact of the enterprise's mode on its management mode, 30 enterprises are studied in this paper and the statistical result is as follows:

Table 1 Impacts of Enterprise Scale on Enterprise Management

\begin{tabular}{|l|l|l|l|l|}
\hline $\begin{array}{l}\text { Enterprise } \\
\text { ownership }\end{array}$ & conditionality & Commitment & $\begin{array}{l}\text { Decentralized } \\
\text { management }\end{array}$ & Supervision \\
\hline $\begin{array}{l}\text { State-owned } \\
\text { enterprises }\end{array}$ & 2 & 2 & 9 & 1 \\
\hline $\begin{array}{l}\text { Non-state-owned } \\
\text { enterprises }\end{array}$ & 5 & 6 & 3 & 2 \\
\hline Total & 7 & 8 & 12 & 3 \\
\hline
\end{tabular}

\subsection{Corporate culture}

Corporate culture is the soul of the enterprise. It is the sedimentary accretion of the enterprise's tradition in process of its development, which is the work philosophy of all staff of the enterprise and the management philosophy of management. Corporate culture in China is more traditional, focusing on ethical and moral principles as well as affection. But in many other countries, the corporate culture pays more attention to the legal system and disciplines. "Working overtime" is also a traditional corporate culture in China. Nearly all Chinese enterprises advocate working overtime, which is not permitted in some countries. In some regions, the enterprise even needs to take the legal liability for enforced overtime.

\subsection{Operational objective}

The operation target is the important direction of the enterprise's future development and guiding light for the enterprise to move forward. An operation target is indispensable if the enterprise wants to get better development. Different enterprises have different development targets and the operation target of the same enterprise is also different in different stage. The operation target also affects the enterprise's HRM mode. Therefore, the enterprise must make a definite operation target while implementing HRM, so as to help itself develop better and faster.

\subsection{Structure of enterprise internal personnel}

The internal personnel are the key for the operation of an enterprise, because it consists of all people engaged in activities of the enterprise. HR managers should select reasonable management mode specific to different staff. Only the reasonable management mode can maximize the resource utilization and effectively reduce the waste of resources, avoiding the brain drain. "Resources" here refers to the human resources.

\subsection{Talent market}

A large number of new talents flow into market every year. But the specific situation is different each year. When the demand for talents is more than the actual amount, individuals have more initiative and the recruiting efforts of enterprises certainly will increase; when the demand for talents is less than the actual amount, enterprises will have more initiative and their recruiting efforts will reduce. If the talent competition is intense, the enterprise needs to improve the benefits of its personnel to enhance the staff's happiness. This can retain talents to the largest extent and avoid the loss that the brain drain brings to the enterprise. 


\section{Countermeasures to Problems Existing in the Human Resources Management Mode}

\subsection{To perfect the management concept}

The improvement of management concept is the first condition to solve problems of HRM. Only the enterprise improve the management concept can it implement management more effective and make staff work closely with each other, and then the operation of the enterprise can more adapt to the development of the times. Therefore, it is essential to perfect the enterprise's performance appraisal system to improve staff's work enthusiasm, prompting the enterprise's better development.

\subsection{To improve the incentive mechanism}

A good incentive mechanism can stimulate staff's work enthusiasm to the greatest extent and improve their happiness, so that they can complete their work more efficiently. This will improve both the quantity and quality of their work. At the same time, a sound incentive mechanism can largely reduce the brain drain, which reduces the cost of the enterprise to a certain extent. Thus, a more reasonable assessment system should be adopted to guide staff to perform better in daily work, making the development of the enterprise more orderly.

\subsection{To attach great importance to the personnel training}

The talent is the root of the development of every enterprise. The talent is essential if an enterprise want to obtain development. So, to improve the personnel training mechanism is the key to enterprise development. Enterprises should lay stress on practical skills of a talent. Only the talent with good practical skills can adapt to the development of the enterprise and promote the enterprise to develop better. At the same time, what enterprises need is not only the introduction of talent, but also personnel training. This is an era in rapidly developing. If an enterprise does not attach importance to the personnel training, its talents will soon lag behind the development of the times and the enterprise itself will be eliminated by times sooner or later. That the enterprise neglects the personnel training is not conducive to the development of the individual, and this will cause serious brain drain. Everyone has the demand for personal development. If an enterprise cannot provide development space for a person, this person will not work in the enterprise for a long time. This will cause the brain drain and bring adverse effects to enterprise development. The enterprise should improve the staff quality of all aspects to help them contribute the greatest power to the enterprise.

\section{Conclusion}

The most important resource in the 21st century is the talent. If a person wants to get development, he must equip himself with outstanding ability; if an enterprise wants to get development, it must get the help of talents. Talent is the basis of an enterprise. In this sense, HR, which manages all personnel of the enterprise, has become the core of the enterprise. In the development of the enterprise, the role of HR cannot be ignored while improving the current state of HR has become the urgent matter now. Only perfect HRM can help the enterprise make best use of every talent to promote the better development of talents and the enterprise. It can also help the enterprise retain talent to the largest extent and reduce the brain drain, avoiding the loss of the enterprise. This will be conducive for both enterprise and individuals to gaining a firm foothold in this era of rapid development. However, due to that the economic development of China is not mature enough, HR development does not get great attention in enterprises, so that HR development of many enterprises is also immature. This is a reason why there is a variety of problems in HRM. For the future development, every enterprise should solve these problems and improve the HRM.

\section{References}

[1]. Liang Xiaohong. A Brief Analysis of Human Resource Management Modes and the Selection Factors [J]. Knowledge Economy, 2015 (14).

[2]. Xia Wei. A Study of the Human Resource Management Modes and Its Selection Factors [J]. Modern Economic Information, 2015 (12). 
[3]. Lou Zheng. About Human Resource Management Modes and the Selection Factors [J]. Enterprise Reform and Management, 2014 (14).

[4]. Zhong Mingxue. Human Resource Management Mode and Its Selection Factors [J]. China High Technology Enterprises, 2015 (22), 176-177

[5]. Yan Xia. Analysis of Human Resource Management Modes and the Selection Factors [J]. Management Observer, 2015 (2), 51-52

[6]. Xiang Shuchu. On the Effective Selection and Application of Human Resources Management Mode [J]. China Business \& Trade, 2015 (9), 41-44 